\title{
TRADITIONAL AND ALTERNATIVE BUSINESS CYCLE DATING PROCEDURES: EVIDENCE FOR THE EURO AREA AND THE CZECH ECONOMY
}

\author{
L'ubica Štiblárová ${ }^{1}$ \\ ${ }^{1}$ Department of Finance, Faculty of Economics, Technical University of Košice, Letná 9, 04001 Košice, Slovak \\ Republic
}

Link to this article: https://doi.org/10.11118/actaun202068010263

Received: 14. 7. 2019, Accepted: 3. 12. 2019

To cite this article: ŠTIBLÁROVÁ L'UBICA. 2020. Traditional and Alternative Business Cycle Dating Procedures: Evidence for the Euro Area and the Czech Economy. Acta Universitatis Agriculturae et Silviculturae Mendelianae Brunensis, 68(1): 263-274.

\begin{abstract}
This paper examines to which extent the results of multivariate principal component analysis based on a set of macroeconomic indicators used by one of the leading economic research organizations - the Centre for Economic Policy Research (CEPR), mimics traditional, univariate Bry and Boschan (1971) business cycle procedure. Using almost 20 years of observations, we estimate the euro area aggregate and the Czech business cycles by classical, as well as alternative multivariate method. Comparison of the euro area aggregate classical business cycle with that of the CEPR reveals minor discrepancies. The estimation of the Czech business cycle using principal component analysis suffers from volatile time series, potentially resulting from a smaller character of the economy. On the contrary, the estimate of the euro area aggregate business cycle reflects quite well Bry and Boschan (1971) procedure, showing rather lagging behavior.
\end{abstract}

Keywords: business cycle, Bry and Boschan procedure, Centre for Economic Policy Research, principal component analysis, euro area aggregate, Czechia

\section{INTRODUCTION}

Over the decades, there has been a long-standing interest in understanding cyclical behavior of economies, identifying key facts and driving forces of the business cycles (Keynes, 1936; Schumpeter, 1939; Burns and Mitchell, 1946; Friedman and Schwartz, 1963; Kydland and Prescott, 1982). In spite of vast empirical and theoretical contribution to this matter, there is still no consensus on the most suitable method to estimate the business cycles or the main cause of these periodical fluctuations, which provides the opportunity to search for new methodological ways how to deal with these issues.

What drives business cycles? Whereas Keynes (1936) in his notorious "General Theory of Employment, Interest and Money" explains a cyclical behavior of the economic activity as a result of fluctuations in the aggregate demand caused by changes in the rate of investment and marginal efficiency of capital, monetarist business cycle theory represented by Friedman and Schwartz (1963) justifies fluctuations by changes in the money supply. On the other hand, Schumpeter (1939) with his theory of innovation claims that the business cycles originate from the occurrence of innovations (e.g., the introduction of a new product, transportation or production method). Kydland and Prescott (1982) bring another perspective to the explanation of the existence of fluctuations by emphasizing real shocks (for this reason known as the real business cycle models or RBC models). Even though their model does not involve the monetary policy, it replicates quite well the variability, persistence and the co- 
movement presented in the empirical data, which might be inconsistent with Friedman (1968), who emphasizes a role of the monetary policy in explaining the business cycle fluctuations.

Besides determining main causes of the economic fluctuations, one of the major methodological issues in the business cycle research remains the fact that the output gap represents an unobservable variable. Empirical studies provide univariate or multivariate analysis using various techniques. However, there has not been a consensus of the most suitable method to estimate the business cycles yet (Kloudová, 2013). In the recent empirical business cycle research, two major approaches have been widely used to define and measure cyclical behavior of the economy - classical and deviation (growth) business cycles approaches.

Classical business cycles approach defines cycles in terms of absolute declines and increases of macroeconomic time series (Schumpeter, 1939). This approach mainly focuses on the asymmetries in the magnitude, duration, variance of the business cycles and dating the turning points. On the contrary, deviation (growth) business cycles approach, which follows neoclassical growth theory, characterizes the business cycles as deviations of the aggregate real output from their long-run trend (Kydland and Prescott, 1990). Whereas classical cycles imply shorter and less frequent recessions, deviation (growth) cycles are characterized by recessions and expansions of approximately same duration, which results from the fact that majority of economies exhibits a growth over time ${ }^{1}$ (Stock and Watson, 1999).

From the methodological point of view, leading organizations ${ }^{2}$ conducting economic research of the business cycles apply specific procedures. These are the National Bureau of Economic Research (NBER), which is responsible for dating the US business cycle since $1854^{3}$, and the Centre for Economic Policy Research (CEPR) determining the chronology of the euro area business cycle. The NBER and the CEPR provide their findings based on a broad set of macroeconomic indicators; their dating procedures often do not include any fixed rule and instead of relying on statistical multivariate methods, prefer personal judgements.

For this reason, the aim of this article is to investigate to what extent the results of multivariate statistical method based on a set of macroeconomic indicators used by the CEPR, mimics traditional, univariate classical business cycle approach. We use so-called, principal component analysis (PCA) as multivariate statistical method and a well-known, classical business cycle approach proposed by Bry and Boschan (1971). Our goal is to examine whether such purely statistical method (PCA) without personal judgment can be applicable to date the business cycles by comparing it with classical business cycle, which serves as a reference.

Even though deviation approach dominates in the recent business cycle empirical studies, we apply classical approach as a reference for several reasons. Firstly, we choose classical business cycle concept to sidestep the issue of spurious cycle identification, which can be present using deviation approach (Canova, 1998). Moreover, we use classical concept due to its transparency and robustness (Bovi, 2005) or the fact that it enables us to conduct more flexible and informative business cycle analysis (Harding and Pagan, 2002). We use this methodology to date the business cycle of the euro area aggregate, for which the CEPR provides its own business cycle chronology, but we also estimate the Czech business cycle, for which such chronology is not available. We choose Czechia as one of the Central and Eastern European (CEE) countries, which as a member country of the Economic and Monetary Union (EMU) should adopt the common currency in future and synchronize with the euro area business cycle, (dis)proving the endogeneity hypothesis ${ }^{4}$.

The rest of this paper is organized as follows; in the second section, we provide a review of specific procedures applied to date the business cycles by leading research organizations. Third section explains methodology used in this paper - classical concept proposed by Bry and Boschan (1971) and multivariate, principal component analysis, including data description. In fourth section, we discuss empirical results and final section concludes our comments.

\section{Review of Business Cycle Dating Procedures}

Whereas empirical studies mostly use one indicator of economic activity to estimate the business cycles, leading organizations conducting economic research in this field apply specific dating procedures on a broad set of macroeconomic indicators.

1 A perfect example is a post-war Japan; growth business cycles can be identified despite of high growth rates, however, we can identify fewer classical recessions due to a smaller number of absolute declines.

2 Presented institutions are non-profit organizations, without any institutional policy position.

3 Although, the business cycle turning points are formally announced since 1979.

4 Here, we follow the Optimum Currency Areas (OCA) theory of Mundell (1961), according to which the optimality of common monetary policy depends on the fact to which extent economies willing to adopt common currency share specific common characteristics, so-called the OCA criteria; the business cycle synchronization is often assumed to be the most crucial one (Darvas and Szapáry, 2008), even the endogeneity hypothesis suggests that country does not have to meet the OCA criteria ex ante, as they can be met ex-post (Frankel and Rose, 1998). 
I: Set of macroeconomic indicators used by the NBER methodology

\begin{tabular}{ll}
\hline & Data Series \\
\hline Gross domestic product (GDP) & Real manufacturing and trade sales \\
Gross domestic income (GDI) & Index of industrial production \\
Average of GDP\&GDI & Real personal income less transfers \\
Macro Advisers historical monthly real GDP & Aggregate weekly hours index in total private industries \\
New Stock-Watson index of monthly GDP & Payroll survey employment \\
New Stock-Watson index of monthly GDI & Household survey employment \\
\hline
\end{tabular}

Source: Own elaboration based on NBER (2010)

Building on Burns and Mitchell (1946), the NBER defines a recession as: "a significant decline in economic activity spread across the economy, lasting more than a few months, normally visible in real GDP, real income, employment, industrial production, and wholesale-retail sales" (NBER, 2012, p. 2). Similarly, an expansionary period presents a substantial increase in the economic activity, which should spread across different sectors of the economy and usually lasts for number of years.

Based on this definition, the NBER maintains the chronology of the US business cycle by examining and comparing various macroeconomic variables (Tab. I). Indicators cover broad economic activity as GDP on the product and income sides, economywide employment, real income, but also specific sectors (e.g., real manufacturing and trade sales). In case of unclear (or conflicting) peaks and troughs in the economy-wide indicators, turning points of the economy-specific indicators can be used to determine the overall dates.

Although the simplest definition in macroeconomics characterizes the recession as a period of two consecutive quarters of negative growth in aggregate output, the NBER does not follow this rule. The NBER's dating procedure does not contain any fixed rule; turning points of the business cycles are determined by personal judgment of the NBER's Business Cycle Dating Committee and following voting procedure with respect to their definition of recession and examined set of macroeconomic indicators. Thus, it is possible that a recessionary period identified by the NBER involves short abrupt period of expansion, followed by further contraction and vice versa. It is up to the Committee to decide whether potential business cycle turning point occurred (NBER, 2010).

The CEPR Business Cycle Dating Committee, which consists of nine CEPR researchers, follows the NBER definition of recession, however, it is slightly tailored to specific European conditions. According to the CEPR, a recession represents: "a significant decline in the level of economic activity, spread across the economy of the euro area, usually visible in two or more consecutive quarters of negative growth in GDP, employment and other measures of aggregate economic activity for the euro area as a whole" (CEPR, 2012, p. 1).
A recessionary period is characterized as a period between peak and following trough, whereas a period between trough and peak is formally defined as expansionary. The CEPR does not specify a depth of expected business cycle phases; in both cases, growth rate can vary.

Unlike the NBER, the CEPR does not take into account monthly indices (e.g., real manufacturing and trade sales or industrial production). It primarily focuses on GDP, consumption, investment and employment (see Tab. II). To eliminate the chance that the Committee would have to reconsider the turning points date due to the data revisions, it involves broad economic activity (GDP), as well as its components and labor market data. Besides that, it also calculates the probability that possible data revisions might lead to the revision of the turning points dates (CEPR, 2012). From 2012, the Committee abandons the requirement that particular turning point has to be observed in most countries of the euro area; this results from the fact that the objective of the CEPR is to date the turning points for the euro area as a whole and it should not be affected by the increasing heterogeneity in the euro area. Hence, it is possible that the CEPR identifies a recession in the euro area as a whole, even if some EA member countries would not show any descending behavior.

Since 1970, the CEPR Committee has identified five complete business cycles (Fig. 1). In contrast to the US economy, the euro area seems to experience fewer peaks and troughs. Although, the CEPR has

II: Set of macroeconomic indicators used by the CEPR methodology

\section{Data Series}

GDP at market prices

Total employment (based on persons)

Household and NPISH final consumption expenditure

Total employment (based on hours worked)

Gross fixed capital formation

Note: The CEPR used different methodology for period 1999-2010 and 1970-1998, see CEPR (2017) Source: Own elaboration based on CEPR (2015) 


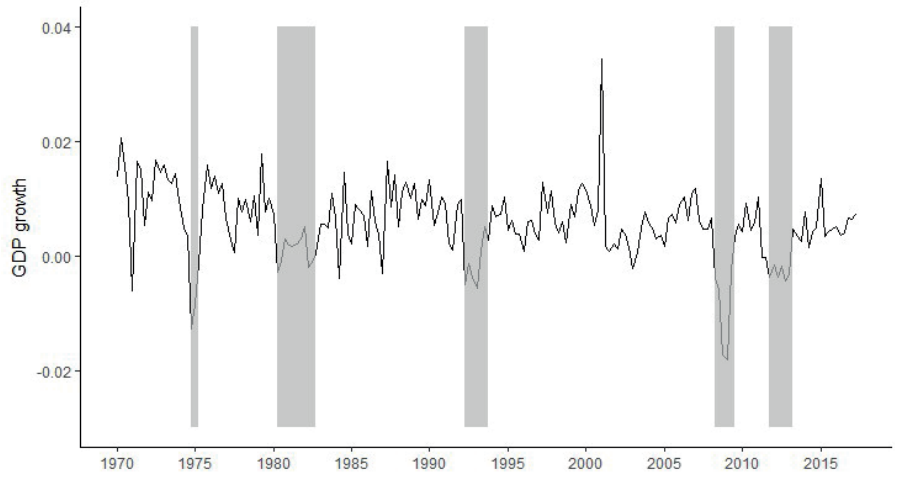

1: Chronology of the euro area business cycle since 1970

Note: The CEPR recession periods are depicted in grey

Source: Own calculations based on CEPR (2015) and OECD (2018)

already identified another peak in 2011Q3 and trough in 2013Q1 after the global financial and economic crisis in 2009, which absent in the US economy. According to the CEPR Committee, the euro area experienced a double-dip recession, resulting into the sluggish, but at a steady pace recovery. The CEPR does not provide a chronology for the European economies separately; this perspective can be partly brought by the Economic Cycle Research Institute (ECRI), which monitors the business cycles of 21 countries from world including 8 European economies (Germany, France, United Kingdom, Italy, Spain, Switzerland, Sweden, and Austria). However, the chronology for other EMU member countries (such as the CEE countries) is not available.

Therefore, the contribution of analysis presented in this paper is twofold; we provide evidence on the Czech business cycle using classical business cycle concept, as well as multivariate principal component analysis, by which we contribute to the limited research of the CEE countries as previous research of the business cycles using principal component analysis has mostly focused on advanced economies (e.g., Andrle, Brůha, and Solmaz, 2016; 2017), the US and Trans-Pacific countries (Aysun and Yagihashi, 2019) or other European countries (Pybus, 2011). This paper provides separated evidence, which complements aggregated results provided by the CEPR. Besides that, we investigate to what extent the results of multivariate principal component analysis based on a set of macroeconomic indicators used by the CEPR, mimics traditional, univariate classical business cycle approach. We verify its applicability to date business cycles and its potential complementary usage to other, traditionally used methods, which could possible broaden methodological procedures in the business cycle research.

\section{MATERIALS AND METHODS}

In this section, we present two methodologies to date business cycle (i.e., the output gap) and its turning points (peaks and troughs) used in this paper - classical business cycle methodology proposed by Bry and Boschan (1971) and alternative, principal component analysis (PCA) based on the CEPR indicators.

\section{Bry and Boschan Procedure}

Classical business cycle methods rely on the classical principles of Burns and Mitchel (1946), with initial goal to replicate the NBER business cycle chronology. Among others, well-known Bry

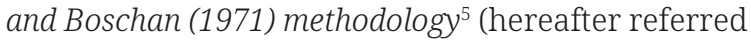
as the BB procedure) was designed as a rulebased procedure, which should capture cyclical movements in the economic activity, abstracting from short-term fluctuations or noise in data. Even though it is applied using only single time series (GDP or industrial production index, respectively), it replicates quite well the rule-free chronology of the NBER and can be also applied to other than the US conditions.

The BB procedure starts with the identification of extreme values and their substitution by interpolated data (Tab. III). Second step involves the smoothing of data by use of 12-month moving average in order to eliminate short-term fluctuations. The BB procedure uses 12-month moving average and potential peaks and trough are identified as points higher (lower) than 5 months on either side. Besides that, it includes the determination of the corresponding turns in Spencer curve and in short-term moving average of 3 to 6 months. Initially, potential turning points are identified within \pm 5 months of selected turns in 12-month moving average, imposing the condition that only business cycles with duration at least 15 months are taking into consideration. 
Procedure for programmed identification of turning points:

I. Determination of extremes and substitution of values.

II. Determination of cycles in 12-month moving average (extremes replaced).

a. Identification of points higher (or lower) than 5 months on either side.

b. Enforcement of alternation of turns by selecting highest of multiple peaks (or lowest of multiple troughs).

III. Determination of corresponding turns in Spencer curve (extremes replaced).

a. Identification of highest (or lowest) value within \pm 5 months of selected turn in 12-month moving average.

b. Enforcement of minimum cycle duration of 15 months by eliminating lower peaks and higher troughs of shorter cycles.

IV. Determination of corresponding turns in short-term moving average of 3 to 6 months, depending on MCD IV. (months of cyclical dominance).

a. Identification of highest (or lowest) value within \pm 5 months of selected turn in Spencer curve.

V. Determination of turning points in unsmoothed series.

a. Identification of highest (or lowest) value within \pm 4 months, or MCD term, whichever is larger, of selected turn a. in short-term moving average.

b. Elimination of turns within 6 months of beginning and end of series.

c. Elimination of peaks (or troughs) at both ends of series which are lower (or higher) than values closer to end.

d. Elimination of cycles whose duration is less than 15 months.

e. Elimination of phases whose duration is less than 5 months.

VI. Statement of final turning points.

Source: Cited from Bry and Boschan (1971, p. 21)

Afterwards, corresponding turns are determined in short-term moving average of 3 to 6 months, which means that the highest (or lowest) values are identified within \pm 5 months of selected turns in Spencer curve. Finally, turning points are determined in the unsmoothed time series based on the results from previous step (short-term moving average) with additional requirements aimed at the elimination of the turns at both ends of time series and shorter business cycles/business cycles phases. Careful compliance of these steps should ensure that short-term declines and increases are eliminated and only permanent fluctuations (business cycles) remain.

\section{Principal Component Analysis}

As second method, we apply a principal component analysis (PCA); this commonly used multivariate procedure allows us to extract a common cyclical component from numerous variables, i.e., to retrieve the output gap from examined countries. By applying this method on a broad set of correlated variables, we reduce a number of dimensions in the Euclidean space, loosing minimum of information (see, e.g., Rencher, 1995; 1998).

The PCA converts the original variables $X_{1}, X_{2}$, $X_{3}, \ldots, X_{p}$ into a set of orthogonal, linearly uncorrelated variables $Y_{1}, Y_{2}, Y_{3}, Y_{p}$, so-called principal components, which contain the maximum variance:

$$
\begin{gathered}
Y_{1}=a_{11} X_{1}+a_{12} X_{2}+\ldots+a_{1 p} X_{p} \\
Y_{2}=a_{21} X_{1}+a_{22} X_{2}+\ldots+a_{2 p} X_{p} \\
Y_{3}=a_{31} X_{1}+a_{32} X_{2}+\ldots+a_{3 p} X_{p} \\
\ldots \\
Y_{p}=a_{p 1} X_{1}+a_{p 2} X_{2}+\ldots+a_{p p} X_{p}
\end{gathered}
$$

where coefficients $a_{i j}$ present weights (loadings). Total variability remains the same as the variance of original variables and principal components equals 1:

$$
a_{i 1}^{2}+a_{i 2}^{2}+\ldots+a_{i p}^{2}=1 \quad \text { for each } i=1,2, \ldots, p .
$$

While the orthogonality of principal components can be defined as:

$$
\begin{aligned}
a_{i 1} a_{j 1}+a_{i 2} a_{j 2}+\ldots+a_{i p} a_{j p}=0 & \text { for all } i \neq j \\
& \text { and } i, j=1,2, \ldots, p .
\end{aligned}
$$

First principal component, which has the greatest variance, plays an important role in determining cyclical fluctuations of the economic activity. Hence, it is generally considered as a proxy for the business cycle, i.e., output gap - see, e.g., application of this approach on the UK output gap (Pybus, 2011) or Slovak output gap (Ódor and Jurašeková Kucserová, 2014). This approach is based on the fact that the output gap presents the most important common 
driver of cyclical behavior of examined variables (i.e., the component with the greatest variance). To calculate this cyclical component, we use combination of standardized variables based on estimated loadings.

The main advantage of this method is that it can include data, which are not an object of frequent data revisions (e.g., soft indicators from business or consumer surveys, mostly). However, the choice of the variables, which should serve as an input data, is disputable. In this case, we follow the procedure of the CEPR and apply the PCA on a set of macroeconomic indicators used by this institution (see Tab. II).

To address the issue of optimal number of principal components for the analysis, we follow the Kaiser rule, according to which we use only principal components with eigenvalues higher than 1 (in case of standardized data) ${ }^{6}$. We also provide the Kaiser-Meyer-Olkin (KMO) test, which is based on the correlation and partial covariance matrices and Bartlett's (1951) test, testing whether correlations between examined variables differ from 0.

\section{Data}

The BB procedure implies univariate analysis; for the indicator of the economic activity, we choose seasonally and calendar adjusted data of industrial production index (IPI). We prefer IPI compared to GDP for several reason. In spite of the fact that GDP presents the broadest indicator of aggregate output, it might be problematic to estimate the business cycle turning points using GDP and the classical business cycle approach because of its steady upward trajectory (see for instance, studies of Artis et al., 2004 or Gigoraş and Stanciu, 2016, dealing with similar issue). Even though IPI does not cover the whole economy, industrial production accounts for a significant share of the aggregate output in the euro area/Czechia. On average, value added of industry represents over 20\% of GDP in the United States, as well as in the European Union and the euro area aggregate, whereas the CEE countries exceed this level with average value of about 30\% of GDP in 2015 (World Bank, 2018).

The PCA presents multivariate analysis, in which we use macroeconomic indicators defined by the CEPR methodology (see variables definition in Appendix). As these variables are in different units of measurement, we standardize each indicator $x$ using the sample mean of the series $\bar{x}$ and the standard deviation $\sigma_{x}$ :
IV: Descriptive statistics

\begin{tabular}{|c|c|c|c|}
\hline Variable & Obs. & Mean & S.D. \\
\hline \multicolumn{4}{|c|}{ Euro area aggregate $^{7}$} \\
\hline IPI & 76 & 99.105 & 4.617 \\
\hline GDP & 76 & 103.705 & 6.115 \\
\hline Consumption & 76 & 0.253 & 0.358 \\
\hline Investment & 76 & 0.284 & 1.641 \\
\hline Employment (pers.) & 76 & 0.180 & 0.281 \\
\hline Employment (hours) & 76 & 0.103 & 0.427 \\
\hline \multicolumn{4}{|c|}{ Czechia } \\
\hline IPI & 76 & 87.400 & 14.128 \\
\hline GDP & 76 & 108.974 & 15.147 \\
\hline Consumption & 76 & 0.601 & 0.647 \\
\hline Investment & 76 & 0.772 & 2.165 \\
\hline Employment (pers.) & 76 & 0.139 & 0.467 \\
\hline Employment (hours) & 76 & 0.096 & 1.363 \\
\hline
\end{tabular}

Source: Own calculations based on Eurostat (2019) and OECD (2019)

$\hat{x}=\frac{x-\hat{x}}{\sigma_{x}}$.

Based on data availability, xour dataset includes almost 20 years of observations as we cover period 2000Q1-2018Q4 for both cases - classical business cycle analysis using the BB procedure and multivariate PCA. We use data on the quarterly basis to fully detect cyclical behavior of examined time series. Descriptive statistics are provided in Tab. IV.

All computations regarding performed analyses were carried out in an $\mathrm{R}$ environment ( $\mathrm{R}$ Core Team, 2016) while using BCDating, psych and tseries packages.

\section{RESULTS AND DISCUSSION}

\section{Dating Classical Business Cycles}

Recession periods identified by classical BB procedure for the euro area aggregate, as well as for Czechia are provided in Fig. 2 (recessions depicted as grey shades).

Even though the Czech industrial production index shows more volatile behavior (see Tab. IV Descriptive statistics), the BB procedure eliminates the short-term fluctuations and determines only permanent fluctuations, with only two recessionary periods compared to the euro area aggregate - in

6 For better interpretation of results, we apply orthogonal rotation VARIMAX (without rotation, it is difficult to differentiate the components - results available upon request). This method mostly approximates to the general requirements of a simple structure by Kaiser (1958).

7 We consider the euro area aggregate reported by Eurostat and OECD, which consists of 19 countries. 
EA

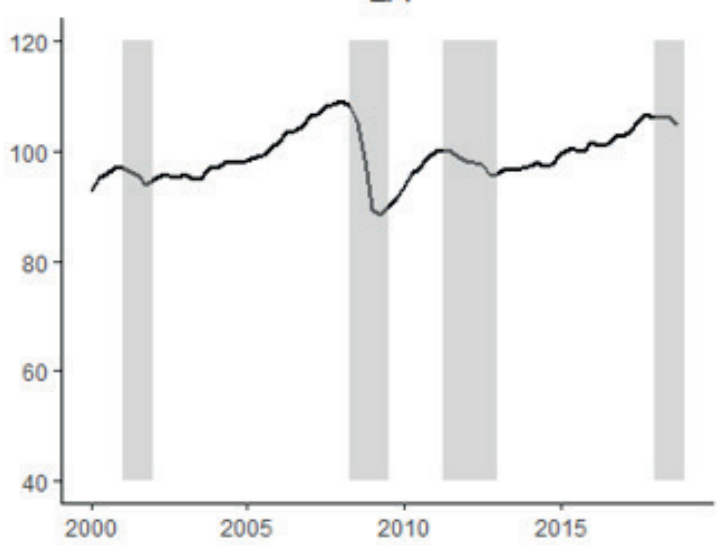

$\mathrm{CZ}$

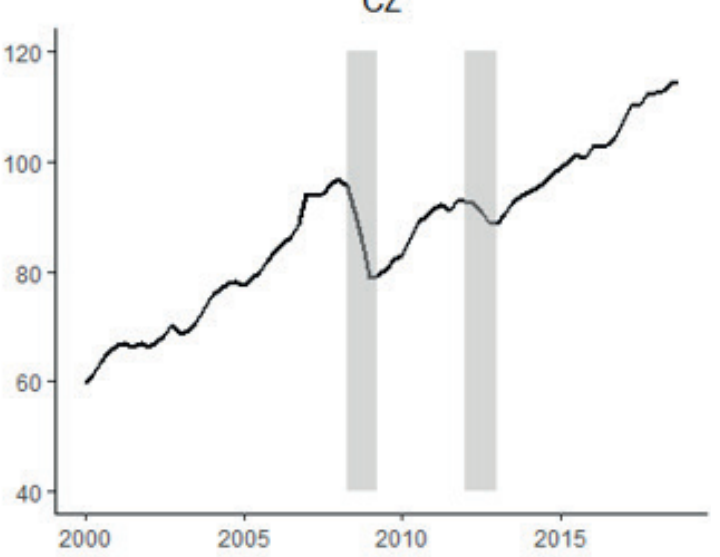

2: Chronology of the euro area (left) and the Czech (right) business cycles using the BB procedure Note: The recession periods identified by the $\mathrm{BB}$ procedure are depicted in grey

Source: Own calculations based on OECD (2019)

2008-09 and 2011-12 (Fig. 2). In case of the euro area aggregate, the BB procedure identifies four recessionary periods starting in years 2001, 2008, 2011 and 2018.

By comparing results of the BB procedure with those of the CEPR (Tab. V), we see minor discrepancies. Unlike the BB procedure, the CEPR did not identify decreasing macroeconomic activity in 2000-01 as a recession; industrial production index, as well as time series of real GDP were decreasing, but the Committee did not declare it as a recession due to the fact that other examined variables did not show declining behavior.

Last euro area recessionary period (starting in 2018Q1) detected by the BB procedure, which is not detected by the CEPR, might be related to the problem of data revisions and consecutive adjustments can erase these findings. However, classical BB procedure almost identically identifies recessions in 2008 and 2011 compared to the CEPR (in some cases, turning point dates are only shifted one or two quarters forward or backward).

$\mathrm{V}$ : Comparison of the turning points from the BB procedure and the CEPR

\begin{tabular}{l|clc}
\hline & \multicolumn{2}{c}{ EA } & CZ \\
\cline { 2 - 4 } & BB procedure & CEPR & BB procedure \\
\hline PEAK & 2000Q4 & & \\
TROUGH & 2001Q4 & & \\
\hline PEAK & 2008Q1 & 2008Q1 & 2008Q1 \\
TROUGH & 2009Q2 & 2009Q2 & 2009Q1 \\
PEAK & 2011Q1 & 2011Q3 & 2011Q4 \\
TROUGH & 2012Q4 & 2013Q1 & 2012Q4 \\
PEAK & 2017Q4 & & \\
\hline SOUr: OWn
\end{tabular}

Source: Own elaboration based on data from OECD (2019) and CEPR (2015)
As we have already mentioned, the CEPR does not provide evidence on the European economies separately. Hence, we contribute to the recent empirical literature by the detection of the classical business cycle turning points of Czechia. By comparing the Czech turning points with those of the euro area aggregate (retrieved by the BB procedure or the CEPR), we see that the timing of the recessions in both countries is highly synchronized. Although, we do not identify recession in 2000-01 for Czechia as for the euro area aggregate; Czechia experienced political and economic crisis sooner - in 1997, which was related to the economic transformation. At the beginning of the $21^{\text {st }}$ century, Czechia performed rather economic growth.

The BB procedure identifies the Great Recession in 2008-09 almost identically for Czechia as for the euro area. Following recessionary period in 2011-12 lasted longer in the euro area aggregate compared to Czechia (Tab. V), but it was weaker compared to the recession in 2008-09 in both economies (Fig. 2). In spite of the fact that Czechia is a member state of the EMU, it still implements independent monetary policy of the inflation targeting. After the recession 2011-12, the Czech National Bank started intervening in 2013 by the use of the exchange rate to boost the economy; such operations stopped in 2017, with plausible results.

A closer look can be done by calculating characteristics of estimated classical business cycles (Tab. VI). Whereas deviation business cycle approach detects symmetric business cycle phases of similar duration or depth, which might be unrealistic and evoke spurious cyclical fluctuations (Canova, 1998), our classical business cycle analysis can reveal asymmetric behavior within particular business cycle phases. This fact is confirmed based on results in Tab. VI, in which we provide characteristics of classical business cycle phases (expansions and recessions, respectively) for the euro area aggregate and Czechia. It is 
VI: Classical business cycle characteristics - the BB procedure

\begin{tabular}{|c|c|c|}
\hline & EA & $\mathrm{CZ}$ \\
\hline \multicolumn{3}{|c|}{ Expansion } \\
\hline Month-over-month change & 0.985 & 1.529 \\
\hline Total change & 12.595 & 17.818 \\
\hline Duration & 17 & 11 \\
\hline \multicolumn{3}{|c|}{ Recession } \\
\hline Month-over-month change & -1.848 & -3.082 \\
\hline Total change & -8.558 & -10.808 \\
\hline Duration & 5 & 4 \\
\hline
\end{tabular}

Note: Duration of the business cycles' phases expressed in quarters, month-over-month and total change of IPI in \%. Calculations are only based on full business cycles (we consider periods between two successive troughs as full business cycles). Uncompleted recessions or expansions at the beginning or the end of data sample are not included. If country experiences two full business cycles, both are included and we provide their average values.

Source: Own calculations based on OECD (2019)

obvious that recessions and expansions differ in their duration and depth in both cases, by which we confirm classical claims about the business cycle asymmetries of Burns and Mitchell (1946); recessions seem to be more intense (in terms of month-over-month change) and shorter compared to the expansions, which are shallower (in terms of month-over-month change), but longer and thus, show higher total change of industrial production index. For instance, the euro area aggregate exhibited on average $0.985 \%$ month-over-month change of industrial production index in expansion, whereas $-1.848 \%$ in recession. Similar behavior can be observed in the case of Czechia.

\section{Retrieving Business Cycles using PCA}

In addition to classical business cycle analysis, we provide results of alternative, principal component analysis. Using Kaiser rule, we reduce number of dimensions from five (total number of the CEPR indicators) to two principal components. Tab. VII provide eigenvalues, alongside with standardized loadings for both principal components in case of the euro area aggregate, as well as in case of Czechia.

In spite of the fact that our data require to use two components, we use first component, which should present the greatest proportion of variance, as a proxy for estimated business cycles (we follow previous studies, see, e.g., Pybus, 2011 or Ódor and Jurašeková Kucserová, 2014). First component for the euro area business cycle presents about $59 \%$ of data variance, which can be considered as satisfactory.

Although, we get smaller proportion for the Czech business cycle (about 31\%), which may affect the quality of the estimate. We depict the first principal component, i.e., estimates of the business cycle of the euro area and Czechia in Fig. 3. To compare results of the PCA with the classical approach, we also include recession shades from the BB procedure (in grey).

The estimate of the euro area aggregate business cycle by the PCA reflects quite well the estimate retrieved by the $\mathrm{BB}$ procedure. Moreover, we confirm our doubts about the recession starting in year 2018 identified by the BB procedure as the PCA does not determine negative output gap at the end of our data sample.

These results might be associated with data revisions; the PCA implies a wider set of macroeconomic variables, from which it can provide additional information important for the proper evaluation of the cyclical behavior. Similarly,

VII: PCA's results - the euro area aggregate and Czechia

\begin{tabular}{|c|c|c|c|c|c|c|}
\hline & \multicolumn{3}{|c|}{ EA } & \multicolumn{3}{|c|}{$\mathrm{CZ}$} \\
\hline & \multirow{2}{*}{$\begin{array}{l}\text { Eigen } \\
\text { values }\end{array}$} & \multicolumn{2}{|c|}{ Loadings } & \multirow{2}{*}{$\begin{array}{l}\text { Eigen } \\
\text { values }\end{array}$} & \multicolumn{2}{|c|}{ Loadings } \\
\hline & & PC1 & $\mathrm{PC} 2$ & & PC1 & PC2 \\
\hline GDP & 2.929 & 0.030 & 0.980 & 1.524 & 0.750 & -0.301 \\
\hline Consumption & 1.065 & 0.810 & -0.270 & 1.238 & 0.080 & 0.720 \\
\hline Investment & 0.487 & 0.790 & 0.100 & 0.853 & 0.001 & 0.770 \\
\hline Employment (pers.) & 0.368 & 0.900 & 0.030 & 0.778 & 0.700 & 0.350 \\
\hline Employment (hours) & 0.151 & 0.920 & 0.140 & 0.608 & 0.600 & 0.090 \\
\hline Proportion of variance & & 0.586 & 0.213 & & 0.305 & 0.247 \\
\hline KMO test & & 0.760 & & & 0.540 & \\
\hline Bartlett's test & & $179.422(<0.001)$ & & & $19.821(0.031)$ & \\
\hline
\end{tabular}

Note: We provide loading regarding first principal component (PC1) and second principal component (PC2). In Bartlett's test, chi square statistics (p-values in parentheses) are provided.

Source: Own calculations based on data from OECD (2019) 
EA

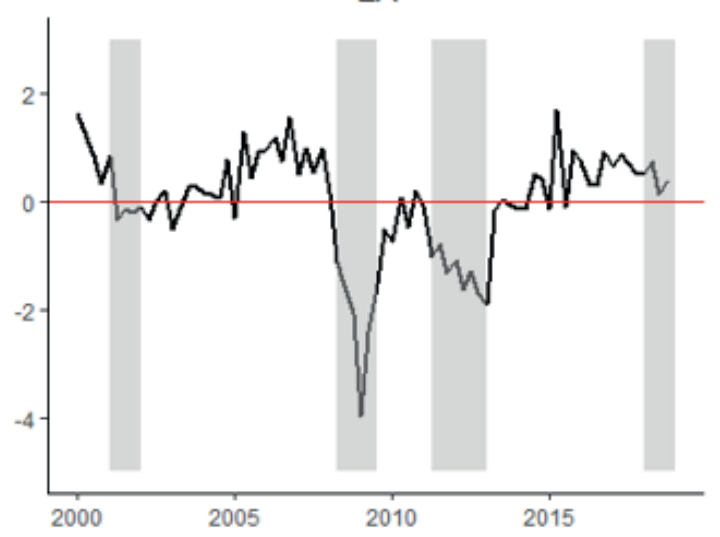

$\mathrm{CZ}$

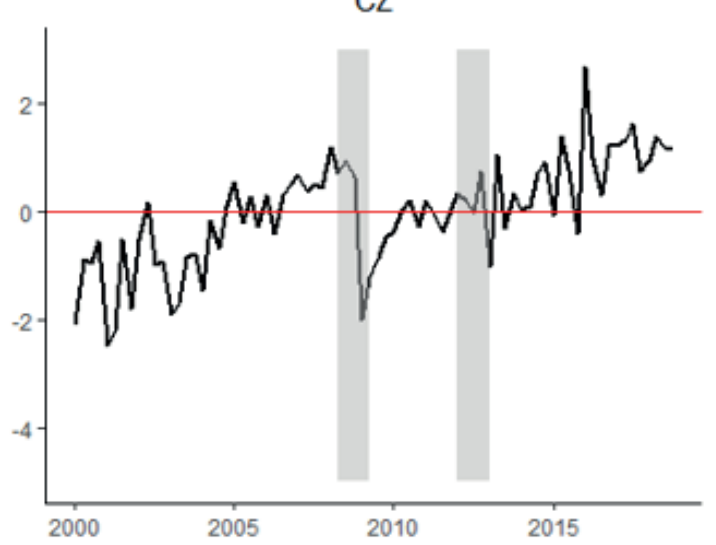

3: Chronology of the euro area (left) and the Czech (right) business cycles using PCA

Note: We depict first principal component (PC1). The recession periods identified by the BB procedure are depicted in grey.

Source: Own calculations based on OECD (2019)

VIII: Comparison of the turning points - the BB procedure and the PCA

\begin{tabular}{|c|c|c|c|c|}
\hline & \multicolumn{4}{|c|}{ Relative to classical business cycles } \\
\hline & \multicolumn{2}{|c|}{ EA } & \multicolumn{2}{|c|}{$\mathrm{CZ}$} \\
\hline & Peak & Trough & Peak & Trough \\
\hline \multirow{2}{*}{ Recession 2001} & 2001Q1 & 2002Q3 & & \\
\hline & +1 & +3 & & \\
\hline \multirow{2}{*}{ Recession 2008} & 2008Q1 & 2010Q1 & 2008Q4 & 2010Q1 \\
\hline & 0 & +3 & +4 & +5 \\
\hline \multirow{2}{*}{ Recession 2011} & 2010Q4 & 2014Q2 & 2011Q1 & 2011Q4 \\
\hline & -1 & +2 & -3 & -5 \\
\hline
\end{tabular}

Note: Peak and trough relative to classical EA/CZ business cycles: (-) denotes the leading position, (+) the lagging position, in quarters. Turning points are identified according to the BB methodology described in Tab. III. Analogously, we identify turning points in the PCA business cycles as the highest (or lowest) values within \pm 5 months (we also follow the simplest and most common rule of thumb defining a recession as a negative output gap in two consecutive quarters (i.e., 6 months)).

Source: Own calculations based on data from Eurostat (2019) and OECD (2019)

the PCA identifies very shallow recession in 2000 (negative output gap close to 0), which confirms decision of the CEPR Committee to not declare this period as a recession as complementary indicators did not exhibit recessionary behavior.

On the contrary, our assumptions about a lower quality of estimation for the Czech economy were accurate. The estimate of the output gap is volatile as the PCA often identifies recessions lasting only one quarter, which would not even fulfil the simplest definition of the recession as a period at least two consecutive negative quarters. Besides that, the PCA estimates very volatile output gap in the period 2000-04, showing recessionary evolution, while the Czech economy experienced rather economic growth in this period.

If we look closer to the components' loadings, we might see different variables participating in dispersion of the first principal component for the euro area and the Czech business cycle. Whereas consumption, investment and employments variables are mostly participating in the euro area business cycle (PC1), we mainly observe employments variables and GDP in the first principal component of the Czech business cycle (Tab. VII), which might be responsible for the volatile behavior of the Czech business cycle.

\section{Timing of the Turning Points}

To compare results of classical BB procedure with those of the PCA, we calculate timing of the turning points identified by both methods for three most significant recessions starting in i) 2001, ii) 2008 and iii) 2011 (Tab. VIII).

Results are quite mixed; whereas the estimate of the euro area aggregate business cycle by the PCA shows rather lagging evolution (relative to classical business cycles), the Czech estimate shows lagging 
behavior in recession 2008, but on the contrary, it shows leading behavior in recession 2011.

However, it would not be appropriate to make such summary for the Czechia as the first component in the PCA is not so strong, i.e., it does not represent a significant proportion of total variance of data. Besides that, we see that Czech data are generally more volatile (see Tab. IV) compared to the euro area aggregate. Czechia as a former socialist country, exhibited transition period, with various structural reforms, which might be associated with higher variance in data and thus, make the estimate using the principal component analysis more unreliable.

\section{CONCLUSION}

Knowledge of the phase of the economy, i.e., whether the economy exhibits expansionary or recessionary period, presents one of the crucial facts affecting implemented country's macroeconomic policies. In spite of vast empirical evidence of the business cycle estimations, i.e., measuring output gaps using various univariate and multivariate methods, there has not been any consensus on the most suitable method yet.

The aim of this article was to investigate to which extent results of multivariate statistical method (principal component analysis) based on a set of macroeconomic indicators used by one of the leading economic research organizations, the CEPR, mimics traditional univariate, classical Bry and Boschan (1971) business cycle approach. As the CEPR dates business cycle turning points based on the personal judgment of the Committee, our goal was to examine purely statistical method and compare its results with reference, classical business cycles. We applied these methodologies on the euro area aggregate and Czechia.

Classical business cycle analysis revealed four recessionary periods in case of the euro area aggregate and two in case of Czechia within selected time period 2000Q1-2018Q4. Comparing classical results with those of the CEPR, we identified minor discrepancies (e.g., a recession at the end of data sample); classical business cycle approach was able to eliminate short-term fluctuations and determine only permanent fluctuations as recessions (in spite of the volatile behavior of the Czech economy). Besides that, classical analysis confirmed asymmetric business cycle phases in terms of their duration and depth.

On the contrary, we were not able to properly estimate the Czech business cycle using principal component analysis due to volatile time series. Although, the estimate of the euro area aggregate business cycle by this method reflects quite well the estimate retrieved by the Bry and Boschan (1971) procedure, showing rather lagging behavior. We also find different variables participating in dispersion of the first principal component for the euro area and the Czech business cycle. Whereas consumption, investment and employments variables are mostly participating in the euro area business cycle (PC1), we mainly observe employments variables and GDP in the first principal component of the Czech business cycle, which might be responsible for the volatile behavior of the Czech business cycle.

For reasons mentioned above, we recommend to use principal component analysis only as complementary method to other traditional procedures or deviation business cycle approaches (e.g., structural production function approach or semi-structural SVAR models), which dominate in the recent empirical literature.

The usage of the principal component analysis in the business cycle research seems to be very useful in cases when indicator of the aggregate output (GDP or industrial production index, respectively) shows dissimilar behavior compared to other macroeconomic variables, i.e., when it is difficult to determine whether the business cycle turning point occurred or not. It is also important to take into account the strength of the principal component (in terms of the proportion of the total variance) and the overall variance of data.

\section{REFERENCES}

ANDRLE, M., BRÜHA, J. and SOLMAZ, S. 2016. Output and Inflation Co-Movement: An Update on Business-Cycle Stylized Facts. IMF Working Paper WP/16/241. IMF.

ANDRLE, M., BRÜHA, J. and SOLMAZ, S. 2017. On the Sources of Business Cycles: Implications for DSGE Models. ECB Working Paper Series No. 2058. EBC.

ARTIS, M. J., KONTOLEMIS, Z. and OSBORN, D. 1997. Business Cycles for G7 and European Countries. The Journal of Business, 70(2): 249-279. 
ARTIS, M. J., MARCELLINO, M. and PROIETTI, T. 2004. Characterising the Business Cycle for Accession Countries. CEPR, Technical Report. CEPR.

AYSUN, U. and YAGIHASHI, T. 2019. The Common Sources of Business Cycles in Trans-Pacific Countries and the US? A Comparison with NAFTA. The World Economy, 42(4): 1077-1109.

BARTLETT, M. S. 1951. The Effect of Standardization on a Chi Square Approximation in Factor Analysis. Biometrika, 38: 337-344.

BOVI, M. 2005. Economic Clubs and European Commitments. Evidence from the International Business Cycles. International Journal of Applied Econometrics and Quantitative Studies, 2(2): 101122.

BRY, G. and BOSCHAN, C. 1971. Cyclical Analysis of Time Series: Selected Procedures and Computer Programs. Columbia University Press.

BURNS, A. F. and MITCHELL, W. C. 1946. Measuring Business Cycles. National Bureau of Economic Research.

CANOVA, F. 1998. Detrending and Business Cycles Facts. Journal of Monetary Economics, 41(3): 475512.

CEPR. 2012. Methodological Note. CEPR Euro Area Business Cycle Dating Committee.

CEPR. 2015. Euro Area Out of Recession, in Unusually Weak Expansion. CEPR Euro Area Business Cycle Dating Committee.

CEPR. 2017. Data Sources. CEPR. [Online]. Available at: https://cepr.org/content/data-sources-1 [Accessed: 2018, January 14].

DARVAS, Z. and SZAPÁRY, G. 2008. Business Cycle Synchronization in the Enlarged EU. Open Economies Review, 19(1): 1-19.

EUROSTAT. 2019. Database. Eurostat. [Online]. Available at: http://ec.europa.eu/eurostat/data/database [Accessed: 2019, July 12].

FRANKEL, J. A. and ROSE, A. K. 1998. The Endogenity of the Optimum Currency Area Criteria. The Economic Journal, 108(449): 1009-1025.

FRIEDMAN, M. 1968. The Role of Monetary Policy. The American Economic Review, 58(1): 1-17.

FRIEDMAN, M. and SCHWARTZ, A. J. 1963. A Monetary History of the United States, 1867-1960. Princeton University Press.

GRIGORAŞ, V. and STANCIU, I. E. 2016. New Evidence on the (De)Synchronisation of Business Cycles: Reshaping the European Business Cycle. International Economics, 147: 27-52.

HARDING, D. and PAGAN, A. 2002. Dissecting the Cycle: A Methodological Investigation. Journal of Monetary Economics, 49(2): 365-381.

KAISER, H. F. 1958. The Varimax Criterion for Analytic Rotation in Factor Analysis. Psychometrika, 23 : 187-200.

KEYNES, J. M. 1936. The General Theory of Employment, Interest and Money. London: Macmillan.

KLOUDOVÁ, D. 2013. Output Gap as Indicator of Inflation - Case for Czech Economy [in Czech: Produkční Mezera jako Indikátor Inflace - Případ pro Českou Ekonomiku]. Politická Ekonomie, 61(5): 639-652.

KYDLAND, F. E. and PRESCOTT, E. C. 1982. Time to Build and Aggregate Fluctuations. Econometrica, 50(6): 1345-1370.

KYDLAND, F. E. and PRESCOTT, E. C. 1990. Business Cycles: Real Facts and Monetary Myth. Federal Reserve Bank of Minneapolis Quarterly Review, 14(2): 3-18.

MUNDELL, R. 1961. The Theory of Optimum Currency Areas. American Economic Review, 51(4): 657665.

NBER. 2010. Business Cycle Dating Committee, National Bureau of Economic Research. NBER. [Online]. Available at: http://www.nber.org/cycles/sept2010.html [Accessed: 2018, January 20].

NBER. 2012. US Business Cycle Expansions and Contractions. NBER. [Online]. Available at: http:// www.nber.org/cycles/US_Business_Cycle_Expansions_and_Contractions_201 20423.pdf [Accessed: 2018, January 20].

OECD. 2018. OECD Quarterly National Accounts Database. OCED.Stat. [Online]. Available at: https:// stats.oecd.org/Index.aspx?DataSetCode=QNA [Accessed: 2018, January 04].

OECD. 2019. OECD Production and Sales Database. OCED.Stat. [Online]. Available at: http://stats.oecd. org/viewhtml.aspx?datasetcode=MEI_REAL\&lang=en [Accessed: 2019, July 12].

ÓDOR, L'. and JURAŠEKOVÁ KUCSEROVÁ, J. 2014. Finding Yeti. More Robust Estimates of Output Gap in Slovakia. Working Paper No. 2/2014. Council for Budget Responsibility.

PYBUS, T. 2011. Estimating the UK's Historical Output Gap. Working Paper No. 1. Office for Budget Responsibility.

R CORE TEAM. 2016. R: A Language and Environment for Statistical Computing. Austria: R Foundation for Statistical Computing. Available at: https://www.R-project.org/ [Accessed: 2019, July 12]. 
RENCHER, A. C. 1995. Methods of Multivariate Analysis. New York: Wiley.

RENCHER, A. C. 1998. Multivariate Statistical Inference and Applications. New York: Wiley.

SCHUMPETER, J. 1939. Business Cycles. A Theoretical, Historical and Statistical Analysis of the Capitalist

Process. New York Toronto London: McGraw-Hill Book Company.

STOCK, J. H. and WATSON, M. W. 1999. Business Cycle Fluctuations in US Macroeconomic Time Series. In: TAYLOR, J. B. and WOODFORD, M. (Eds.). Handbook of Macroeconomics. Elsevier, pp. 3-64.

WORLD BANK. 2018. World Development Indicators Database. World Bank. [Online]. Available at: http://databank.worldbank.org/data/reports.aspx?source=world-development-indicators [Accessed: 2018, January 07].

\section{APPENDIX}

Appendix A: Variables definition and data sources

\begin{tabular}{llll}
\hline \multicolumn{1}{c}{ Variable } & \multicolumn{1}{c}{ Variable definition } & \multicolumn{1}{c}{ Indicator used as an input } & \multicolumn{1}{c}{ Source } \\
\hline IPI & Production of total industry & Index 2015=100 & OECD (2019) \\
GDP & GDP at market prices & Chain linked volumes, index 2005=100 & Eurostat (2019) \\
Consumption & $\begin{array}{l}\text { Household and NPISH final } \\
\text { consumption expenditure }\end{array}$ & $\begin{array}{l}\text { Chain linked volumes, percentage change } \\
\text { over previous period }\end{array}$ & Eurostat (2019) \\
Investment & Gross fixed capital formation & $\begin{array}{l}\text { Chain linked volumes, percentage change } \\
\text { over previous period }\end{array}$ & Eurostat (2019) \\
Employment (pers.) & $\begin{array}{l}\text { Total employment domestic } \\
\text { concept }\end{array}$ & $\begin{array}{l}\text { Percentage change over previous period } \\
\text { (based on persons) }\end{array}$ & Eurostat (2019) \\
Employment (hours) & $\begin{array}{l}\text { Total employment domestic } \\
\text { concept }\end{array}$ & $\begin{array}{l}\text { Percentage change over previous period } \\
\text { (based on hours worked) }\end{array}$ & Eurostat (2019) \\
\hline
\end{tabular}

Source: Own elaboration 